\title{
Larval competition within seeds: From the behaviour process to the ecological outcome in the seed beetle Callosobruchus maculatus
}

\author{
RAUL N. C. GUEDES, ${ }^{1,2 \star ~ N E L S A ~ M . ~ P . ~ G U E D E S ~}{ }^{1,2}$ AND ROBERT H. SMITH ${ }^{3}$ \\ ${ }^{1}$ Departamento de Biologia Animal, Universidade Federal de Viçosa, Viçosa, MG 36571-000, Brazil \\ (Email: guedes@ufv.br); ${ }^{2}$ Department of Biology, University of Leicester, Leicester, and ${ }^{3}$ School of \\ Applied Sciences, University of Huddersfield, Queensgate, Huddersfield, UK
}

\begin{abstract}
Environmental conditions experienced by organisms during development can have profound impacts on adult fitness and behaviour. Internally feeding larvae unable to leave the seed selected by their mother face limitations of resource suitability and competition. The host seed may guide the larval behaviour within the seed leading to differential intensity of competition and determining its process and outcome, which varies in strains of the legume seed beetle Callosobruchus maculatus (Coleoptera: Bruchidae). However, the intensity, process and outcome of larval competition in different hosts have yet to be simultaneously considered, the objective of the present study. Here we assessed the intensity, process and outcome of intrastrain larval competition as related to host type, and how they are interrelated. Larval competition was faced with two distinct strategies - scramble and contest competition depending on the insect strain and host seed species. The intensity of competition did not show any straight link with the process and outcome of competition. Only a single strain showed a contest competition process with likely interference between larvae, while the four other strains studied showed the process of scramble competition. The process of scramble competition, however, led to variable outcomes in mung beans based on larval competition curves. Such differences were not apparent on cowpea seeds and either the plateau or the peak expected on the larval fitness curves were not reached preventing the distinction of the competition outcome, a likely consequence of the egg laying behaviour of these strains limiting the maximum number of eggs laid per seed. Seed host species rather than seed size are the likely cause of the differences observed from the initial expectation. The strain showing the process of contest competition increased larval fitness with density of larvae emerged per seed regardless of the host species, an unexpected outcome based on theoretical models. In this case the egg laying behaviour of the adult female is probably the main fitness determinant of its progeny.
\end{abstract}

Key words: bruchidae, contest competition, scramble competition, Vigna radiata, Vigna unguiculata.

\section{INTRODUCTION}

Competition between animals for limited resources is a fundamental determinant of life-history and behaviour. Nicholson (1954) originally defined two distinct strategies of intraspecific competition contest and scramble competition. These competition strategies are commonly defined in terms of resource use (e.g. Varley et al. 1973). In scramble competition all members of a population have equal access to the limited resource. In contest competition the successful competitor secures as much of the governing resource as needed for its survival and reproduction.

Nicholson (1954), however, also recognized the process by which competition takes place, which is an individual-level phenomenon, unlike the populationlevel concept referred to above. In the contest process

${ }^{\star}$ Corresponding author.

Accepted for publication December 2006. of competition there is interference activity (namely behaviour interference, such as active aggression) between competitors, as if they are competing for a prize when there is only one winner (Nicholson 1954), but the proximal mechanisms are only poorly known for seed beetles (Smith \& Lessells 1985; Toquenaga 1993; Alves-Costa \& Knogge 2005). In the process of scramble competition there is accommodation of all competitors allowing increased survival, but with reduced individual resource gain and consequently lower adult weight at emergence, unlike what is expected under the contest process (Miller 1967; Giga \& Smith 1991; Lale \& Vidal 2001). However, scramble and contest strategies of competition have been frequently defined by their outcome based on the relationship between number (or fitness) of survivors versus the initial numbers (Varley et al. 1973; Bellows 1982). Again, like Nicholson's resource-based concept of competition, competition outcome is a populationbased concept. 
The distinction between the behavioural process of competition and the population outcome is important (Smith \& Lessells 1985; Smith 1990). The process is a consequence of intrinsically disruptive selection on larval competition strategies, while the outcome also depends on how much resource is required for development in relation to its availability within a resource patch (Smith \& Lessells 1985). Therefore, a contest type of outcome may come about even without direct behavioural interference depending on the resource and the proximal mechanisms involved with consequences on life history evolution and its practical implications (Smith 1990; Colegrave 1994, 1995, 1997; Nylin 2001; Guedes et al. 2003a). The large larvae with high metabolic rate reported in some bruchid strains for instance may lead to an outcome predicted by contest competition despite showing a scramble process of competition (Credland et al. 1986; Smith 1990; Daniel \& Smith 1994; Guedes et al. 2003a).

Competition is particularly a problem for seed beetles whose larval stages are spent within a single seed. This is an example of a closed system where the young are unable to avoid competition with conspecifics if multiple eggs are laid on the same seed, especially considering semelparous insects with non-feeding adults (Smith 1990, 1991; Colegrave 1994). The effects of larval competition of these granivore species affect the evolution of behaviour, while the behaviour has consequences for the rate of population growth and stability, thus closely linking behaviour and ecology (Smith \& Lessells 1985). The system of larval competition in Callosobruchus spp. is a useful model often used for such studies (Smith \& Lessells 1985; Smith 1990, 1991; Colegrave 1994, 1995, 1997; Takano et al. 2001; Mano et al. 2002; Messina 2004; Vamosi 2005). However, the intensity, process and outcome of larval competition are rarely simultaneously considered.

The cowpea weevil, Callosobruchus maculatus (F) (Coleoptera: Bruchidae), is an agricultural pest of seed legumes throughout tropical and subtropical regions of the world, which shows broad variation in biological traits in geographically distinct strains (Southgate 1978; Credland \& Dick 1987; Smith 1990; Shade et al. 1999; Guedes et al. 2003a,b). This is the likely consequence of the discontinuous nature of the stored seed environment and periodic inbreeding in C. maculatus (Tran \& Credland 1995). The expression of this variation is likely influenced by the host seed and may help in understanding the local evolution of these strains and how they relate to their distinct larval competition strategies, which range from scramble to contest (Smith \& Lessells 1985; Smith 1990; Colegrave 1997; Horng 1997; Takano et al. 2001; Messina 2004).

The objective of the present investigation was to assess the intensity, process and outcome of intrastrain larval competition as related to host type, and how they are interrelated. Intensity of competition was determined by adult emergence curves, while the individual-based process of competition was recognized by adult weight curves and the population-based outcome of competition was recognized by curve estimates of total larval fitness (Smith \& Lessells 1985; Horng 1997). This initiative would allow us to provide support for the game theoretical predictions, which recognize the distinction between competition process and outcome and suggest the prevalence of the contest competition outcome in realistic settings of bruchid populations, particularly with small host seeds such as mung bean (Smith \& Lessells 1985; Smith 1990; Colegrave 1994, 1995).

Shifting to larger seeds leads to decreased intensity of competition and consequently favours the scramble process of competition as recently demonstrated by Messina (2004). In the present study we expected reduced intensity of competition with a larger host seed (i.e. cowpea). We also expected prevalence of the scramble process of competition in strains either collected or maintained in larger host seeds, and higher incidence of a scramble outcome in cowpea seeds and a contest outcome in mung bean for these strains. In contrast, we did not expect any effect of larval density on larval fitness for strains originated or maintained in small host seeds as a result of their behaviour, regardless of seed host size.

\section{METHODS}

\section{Insect populations}

The five geographically distinct strains of $C$. maculatus used here are the same as used by Guedes et al. (2003a) in respirometry studies. The strain from Brazil was originally collected in Campinas in 1975, whereas the Nigeria strain was collected in Ibadan in 1981. They were both obtained from cowpeas, as was the Uganda strain collected in Kawanda in 1982. The Yemen strain was collected from lentils in Damar in 1976. These four strains were derived from stock cultures maintained at the UK National Resources Institute. The India strain was originally collected from mung beans (Vigna radiata) and blackgram (Vigna mungo) in Tirunelveli in 1979. It was derived from stock cultures maintained at the Department of Biology, Utah State University, USA. All of the strains, except the India strain, have been maintained on cowpea for several years. The India strain has been maintained on mung bean, but new lines were established in cowpea for three generations before use in this investigation. The insect cultures were maintained using the same procedures and densities in an 
environmentally controlled room, where the experiments were also carried out at $30 \pm 2{ }^{\circ} \mathrm{C}, 70 \pm 10 \%$ r.h. and $12 \mathrm{~h}$ photoperiod (LD 12:12 h).

\section{Competition experiments}

Black-eyed cowpeas and mung beans were subjected to different infestation densities by allowing two, four or eight pairs of newly emerged adults (between 24 and $48 \mathrm{~h}$ old) from each strain to mate and oviposit on batches of 20 seeds of either host species for $24 \mathrm{~h}$. After an additional 4 days, the seeds were separated in individual wells of 24 -well insect cell culture plates. Unhatched eggs (which remain transparent) were scraped off with a scalpel to leave a known number of larvae in each seed.

Last instar larvae form translucent 'windows' in the seed host by excavating up to the coat without breaking through. Once such emergence windows began appearing, observations were made daily and the emergence, sex, and weight of each adult and developmental time were recorded on the day of emergence (Giga \& Smith 1991). The emerged adults were sexed using elytral patterns (Southgate et al. 1957) and individually weighed on a Cahn electrobalance.

The number of insects per treatment was made inversely proportional to density (rounded to the near integer) to make the within-treatment variance homogeneous between larval densities, as suggested by Giga and Smith (1991). Therefore, 24 seeds of the one larva seed density were used, two replicates of 12 larvae per seed and so on, such that the average (total) number of larvae in each density treatment was 24 (ranging from 22 to 28). All integer densities between one and 12 larvae per seed were aimed for, but only obtained for the Brazil strain in both hosts and Nigeria strain in cowpea. The larval densities obtained in cowpea seeds ranged from 10 to 12 and in mung bean seeds they ranged from 5 to 12 .

\section{Data processing and analyses}

Data from cowpea and mung bean were treated independently since some of the traits here assessed (e.g. weight) may not be suitable surrogates for fitness when comparing individuals developing in different hosts (Timms 1998; Vamosi 2005). Adult emergence $(y)$ data were fitted against density of emerged larvae $(x)$ using a model derived from Horng (1997): $y=\alpha x^{-\beta}$, where $\alpha$ is a measure of the quality of the host for the seed beetles (i.e. the adult emergence from a seed with a single larvae emerged); and $\beta$ is the competition coefficient (the higher is $\beta$, the higher is the competition). The curve fitting procedure of SigmaPlot 2000 was used for this purpose (SPSS 2000). The data of female and male weight, developmental time and proportion of females (no. females/total no insects) were subjected to analyses of covariance with the insect strains as the independent variable and the density of larvae hatched as the covariate (PROC GLM; SAS Institute 1997). Complementary regression analyses were carried out for each strain whenever necessary (PROC REG; SAS Institute 1997). Larvae sharing a seed were regarded as pseudoreplicates of the effect of density since their measures are confounded by a common bean environment. Therefore, only average results from different seeds were considered as replicates.

Larval survival and weight of adults at emergence are affected by competition (Smith \& Lessells 1985). Both fecundity and longevity are related to weight and should be included in any measure of fitness (Anderson 1978), as is well established for C. maculatus (Smith \& Lessells 1985; Credland et al. 1986; Messina 1991). Therefore, the female biomass (mg) produced per seed, obtained by combining the probability of female emerging and female weight (as a measure of fecundity), was used as a measure of total larval fitness to generate the larval competition curves (Smith \& Lessells 1985). SigmaPlot 2000 was also used to fit these curves (SPSS 2000), after analysis of covariance when the assumptions of such analysis were met.

\section{RESULTS}

\section{Adult emergence}

The adult emergence curves for the insect strains in cowpea and mung bean were markedly different regarding both host quality ( $\alpha$ parameter in the model $\left.y=\alpha x^{-\beta}\right)$ and intensity of competition ( $\beta$ parameter of the same model) (Fig. 1). The host quality was similar for all of the strains in cowpea showing high adult emergence $(\alpha>98.50 \%)$ without the effect of competition (Fig. 1a), unlike mung bean seeds that showed significantly poor quality for larvae from Uganda and Yemen $(\alpha=67.77 \pm 9.89$ and $67.22 \pm 8.13 \%$ adult emergence without competition, respectively) (Fig. 1b). Larval competition in cowpea seeds was more intense, but similar in the Brazil and India strains $(\beta=0.30 \pm 0.05$ and $0.30 \pm 0.06$, respectively) than in the strains from Nigeria, Uganda and Yemen, whose larval competition was also similar $(\beta=0.15 \pm 0.05$, $0.17 \pm 0.06$ and $0.13 \pm 0.05$, respectively). In mung bean, intensity of competition was particularly strong in the India strain $(\beta=0.77 \pm 0.08)$, followed by the Brazil, Nigeria and Uganda strains $(\beta=0.38 \pm 0.07$, $0.32 \pm 0.08$ and $0.26 \pm 0.10$, respectively). Intensity of competition was lowest among larvae from Yemen in mung bean $(\beta=0.13 \pm 0.05)$. 
a) Cowpea

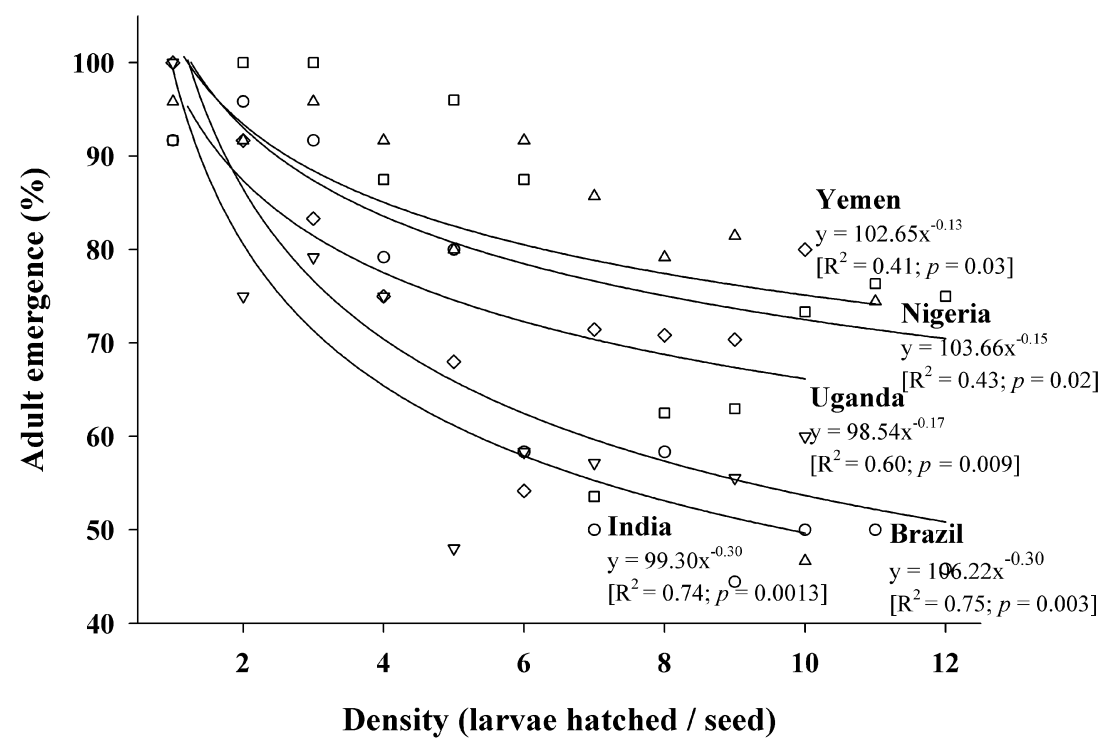

b) Mung bean

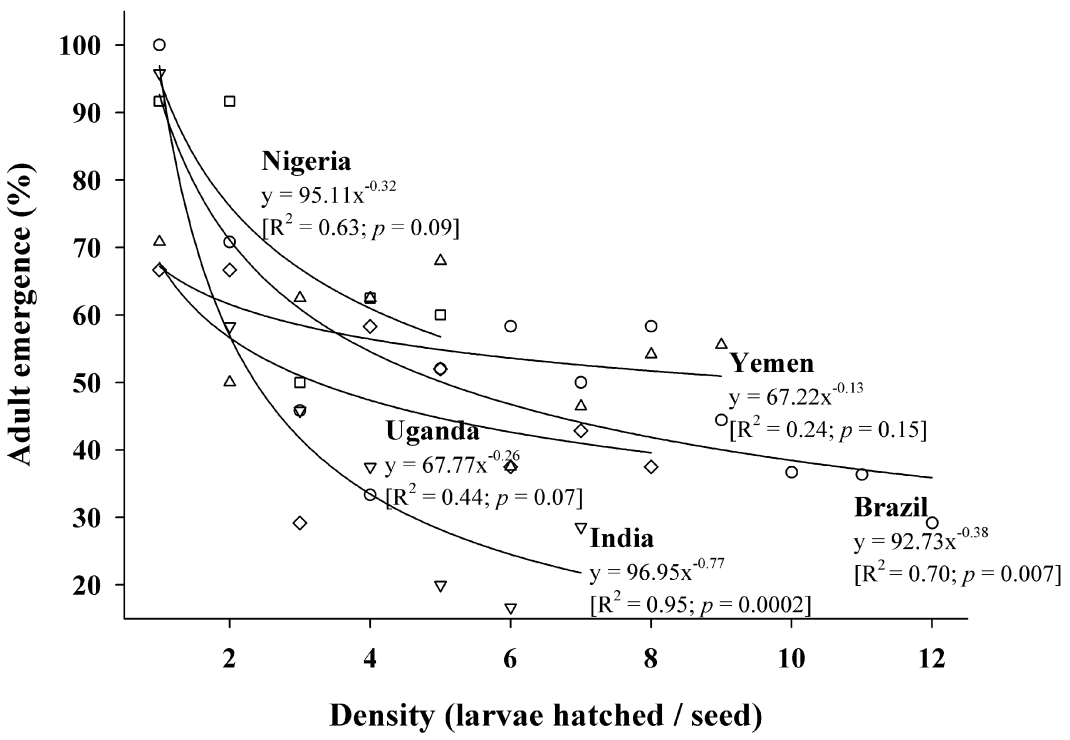

Fig. 1. Adult emergence (\%) of five strains of Callosobruchus maculatus subjected to increasing levels of larval competition in seeds of two host species, cowpea and mung bean. Each symbol represents the observed results for each strain [Brazil $(\bigcirc)$, India $(\nabla)$, Nigeria $(\square)$, Uganda $(\diamond)$, Yemen $(\triangle)]$.

\section{Female and male weight}

Analyses of covariance for female weight as a function of larval density in legume seeds indicated significant effects of strain and density in cowpea, without significant interaction between strain and density (Table 1). The slopes of the curves of female weight $\times$ density of larvae hatched were therefore similar $(P>0.15)$, suggesting a similar process of competition. Indeed, the rate of decrease in female weight with increased larval competition was indistinguishable in the strains from
Brazil, Nigeria and Uganda $(-0.08 \pm 0.01 ; P>0.15)$ (Fig. 2a). The Yemen strain also showed a similar rate of decline in female weight with increased competition $(-0.12 \pm 0.02)$, but always with heavier females than the strains from Brazil, Nigeria and Uganda (Fig. 2a). Analysis of covariance for female weight as a function of larval density in mung bean indicated significant interaction between strain and larvae density (Table 1), in contrast with the results in cowpea seeds. Again the curves for the Brazil, Nigeria and Uganda strains were indistinguishable $(P>0.15)$, but with a 
Table 1. Analyses of covariance of female and male weight (mg) and developmental time (days) of five strains of Callosobruchus maculatus subjected to different larval densities in seeds of two hosts, cowpea and mung bean

\begin{tabular}{|c|c|c|c|c|c|c|c|c|c|c|}
\hline \multirow[b]{2}{*}{ Host } & \multirow{2}{*}{$\begin{array}{l}\text { Source of } \\
\text { variation }\end{array}$} & \multicolumn{3}{|c|}{ Female weight (mg) } & \multicolumn{3}{|c|}{ Male weight (mg) } & \multicolumn{3}{|c|}{ Developmental time (days) } \\
\hline & & d.f. & $F$ & $P$ & d.f. & $F$ & $P$ & d.f. & $F$ & $P$ \\
\hline \multirow[t]{5}{*}{ Cowpea } & Model & 54 & 8.47 & $<0.001^{\star}$ & 54 & 17.56 & $<0.001^{\star}$ & 54 & 3.48 & $<0.001^{\star}$ \\
\hline & Error & 145 & - & - & 131 & - & - & 9284 & - & - \\
\hline & Strain $(S)$ & 4 & 60.74 & $<0.001^{\star}$ & 4 & 165.02 & $<0.001^{\star}$ & 4 & 4.96 & $0.007^{\star}$ \\
\hline & Larval density (D) & 11 & 4.91 & $<0.001^{\star}$ & 11 & 3.63 & $0.002^{\star}$ & 11 & 5.93 & $<0.001^{\star}$ \\
\hline & $\mathrm{S} \times \mathrm{D}$ & 39 & 0.92 & 0.60 & 39 & 0.93 & 0.59 & 39 & 1.82 & $0.003^{\star}$ \\
\hline \multirow[t]{5}{*}{ Mung bean } & Model & 42 & 10.91 & $<0.001^{\star}$ & 39 & 8.71 & $<0.001^{\star}$ & 40 & 5.08 & $<0.001^{\star}$ \\
\hline & Error & 91 & - & - & 83 & - & - & 199 & - & - \\
\hline & Strain $(S)$ & 4 & 20.56 & $<0.001^{\star}$ & 4 & 37.69 & $<0.001^{\star}$ & 4 & 0.35 & 0.85 \\
\hline & Larval density (D) & 11 & 11.94 & $<0.001^{\star}$ & 11 & 4.74 & $<0.001^{\star}$ & 11 & 1.49 & 0.12 \\
\hline & $\mathrm{S} \times \mathrm{D}$ & 27 & 3.44 & $0.001^{\star}$ & 24 & 1.13 & 0.34 & 25 & 0.35 & 0.99 \\
\hline
\end{tabular}

* Significant at $P<0.05$.

rate of female weight decline with competition smaller than that observed for the Yemen strain $(-0.27$ \pm 0.03 and $-0.50 \pm 0.05$, respectively) (Fig. 2b). The heavier females from Yemen probably lead to the steeper decline of female weight with increasing larval density. Females from the India strain were also heavier, but their weight did not decline with increased larval competition in mung bean, as would be expected for a contest process of larval competition (Fig. 2).

Male weight showed similar results and trends to those observed for female weight with increased larval competition (Table 1; Fig. 3). The rate of male weight decline with competition in the strains of Brazil, Nigeria and Uganda was indistinguishable $(-0.05$ \pm 0.01 and $-0.20 \pm 0.02$ for cowpea and mung bean, respectively; $P>0.15)$. Males from Yemen showed intermediate weight to India and the other strains with a rate of decrease $(-0.04 \pm 0.01)$ similar to Brazil, Nigeria and Uganda when in cowpea and when in mung bean $(-0.20 \pm 0.03$ for Yemen and $-0.20 \pm 0.02$ for Brazil, Nigeria and Uganda) (Fig. 3b). Male weight of the India strain was not affected by competition either in cowpea or in mung bean (Fig. 3).

The decrease of adult weight (for both females and males) with density indicates a scramble competition process. This was observed in cowpea and also in mung bean for both female and male weight of the strains from Brazil, Nigeria and Uganda, which were indistinguishable, and also for the insects from the Yemen strain, which were heavier.

\section{Developmental time and female proportion}

Analyses of covariance for developmental time as a function of strains and larval density indicated signifi- cant interaction between strains and larval density for cowpea, but no significant differences were observed for mung bean $(26.58 \pm 0.16$ days) (Table 1$)$. Developmental time increased with larval density for all strains reared on cowpea except Brazil, which showed an inverse relationship $(-0.13 \pm 0.02)$ (Fig. 4). There was very small variation in female proportion $(0.48 \pm 0.01)$, which was not at all affected by the larval density in the present study, regardless of the host seed species. Developmental time and female proportion do not seem to bear any direct relationship with the intensity and the process of competition. However, the longer developmental time observed at higher larval densities in four of the strains is indicative of competition in cowpea, but not in mung bean. Competition is also intense in mung bean based on the adult emergence curves, despite the lack of effect of larval density on larval development reinforcing the lack of direct relationship between intensity and process of competition.

\section{Larval competition curves}

The competition curves related total larval fitness (as female biomass produced per seed) with density of larvae hatched (Fig. 5). Competition curves reaching a plateau at higher densities indicate a contest outcome, while a peak indicates a scramble outcome (Smith \& Lessells 1985). Both types of outcome can take place with the scramble competition process and no fitness variation is expected as outcome for the process of contest competition (Smith \& Lessells 1985; Smith 1990, 1991).

Analysis of covariance for larval competition in cowpea seeds as a function of strains and larval density indicated significant interaction between strains and larval density (Table 2). The larval 


\section{a) Cowpea}

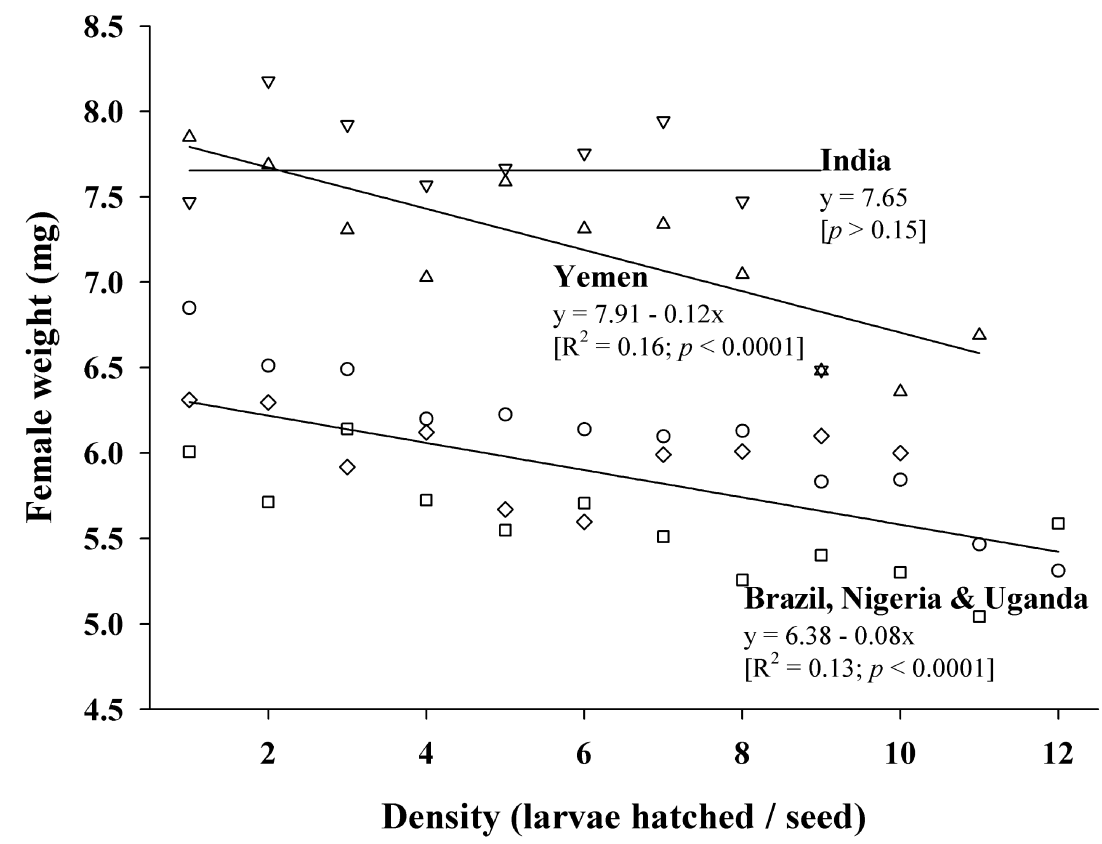

b) Mung bean

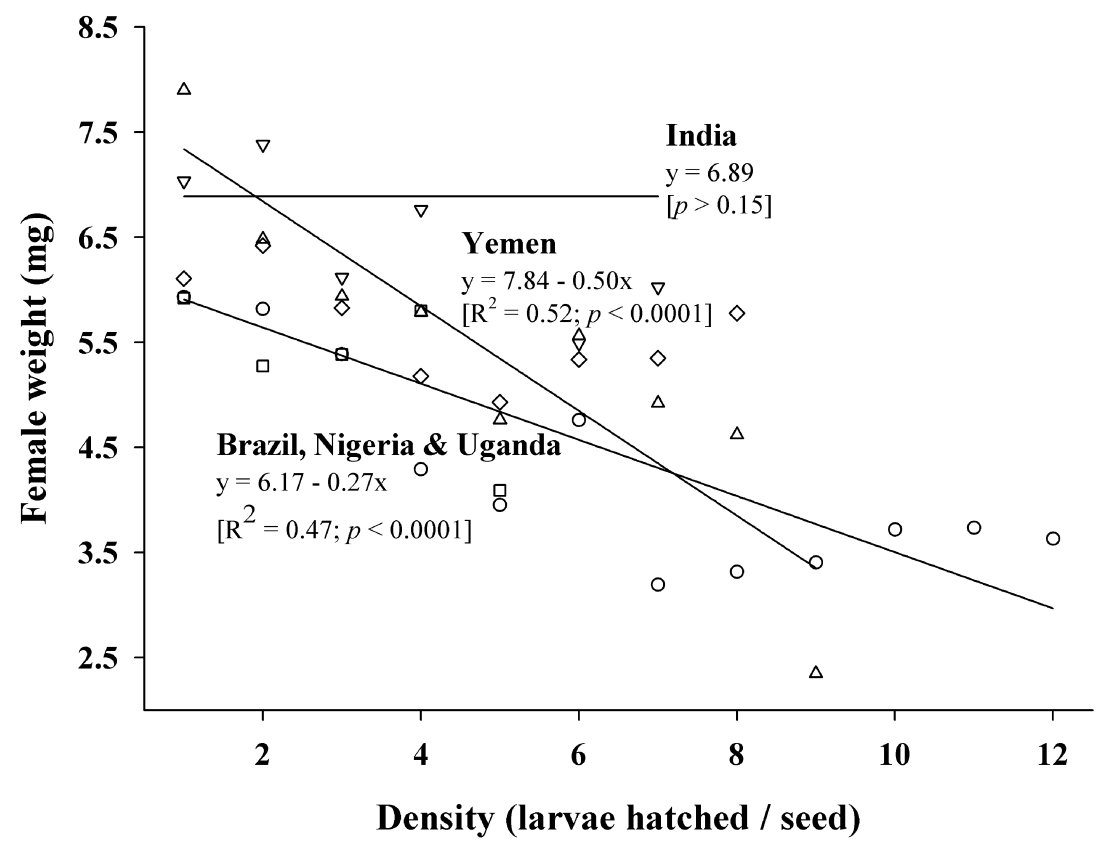

Fig. 2. Weight at emergence (mg) of females from five strains of Callosobruchus maculatus subjected to increasing levels of larval competition in seeds of two host species, cowpea and mung bean. Each symbol represents the mean of the observed results for each strain $[$ Brazil $(\bigcirc)$, India $(\nabla)$, Nigeria $(\square)$, Uganda $(\diamond)$, Yemen $(\triangle)$ ].

competition curves obtained from cowpea seeds bestfitted the exponential model $\left(y=\alpha x^{\beta}\right)$ with steeper increase in fitness for the Yemen strain $(\beta=0.80 \pm 0.20)$, and lower rate of fitness increase with the Brazil strain $(\beta=0.38 \pm 0.13$; Fig. $5 \mathrm{a})$. The larval competition curves of the strains from India, Nigeria and Uganda were indistinguishable in cowpea $(P>0.05$; Fig. 5a). No distinct plateau was reached for these strains at the densities obtained for this study in cowpea preventing the recognition of the 


\section{a) Cowpea}

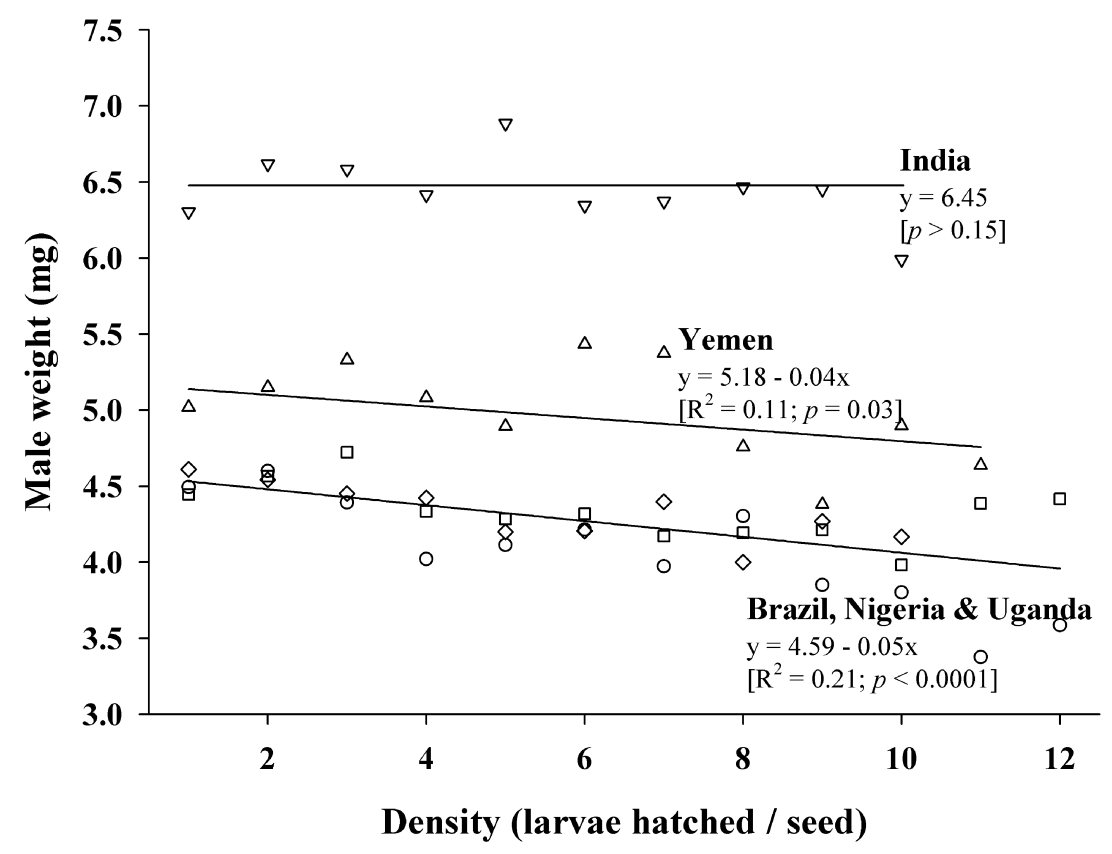

b) Mung bean

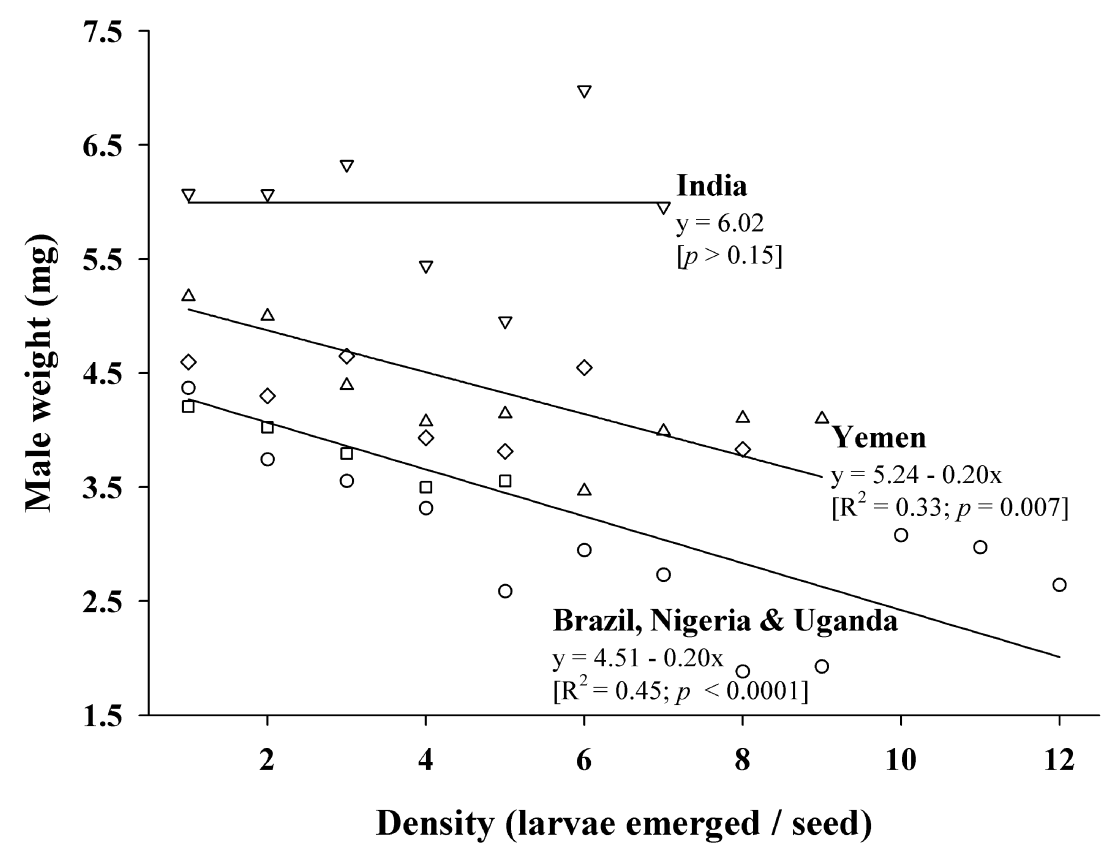

Fig. 3. Weight at emergence (mg) of males from five strains of Callosobruchus maculatus subjected to increasing levels of larval competition in seeds of two host species, cowpea and mung bean. Each symbol represents the mean of the observed results for each strain [Brazil $(\bigcirc)$, India $(\nabla)$, Nigeria $(\square)$, Uganda $(\diamond)$, Yemen $(\triangle)$ ].

outcome, unlike what was obtained in mung bean (Fig. 5b). The models of total larval fitness were distinct in mung bean with fitness increased with density for India and Nigeria strains, which seems limited by the maximum number of eggs laid in the seed, as also observed for all of the strains in cowpea seeds. In contrast, the other strains showed humped curves with peaks of larval fitness at the larval densities of 10, 7 and 3 larvae emerged per seed for the strains of Brazil, Uganda and Yemen, respectively (Fig. 5b). 


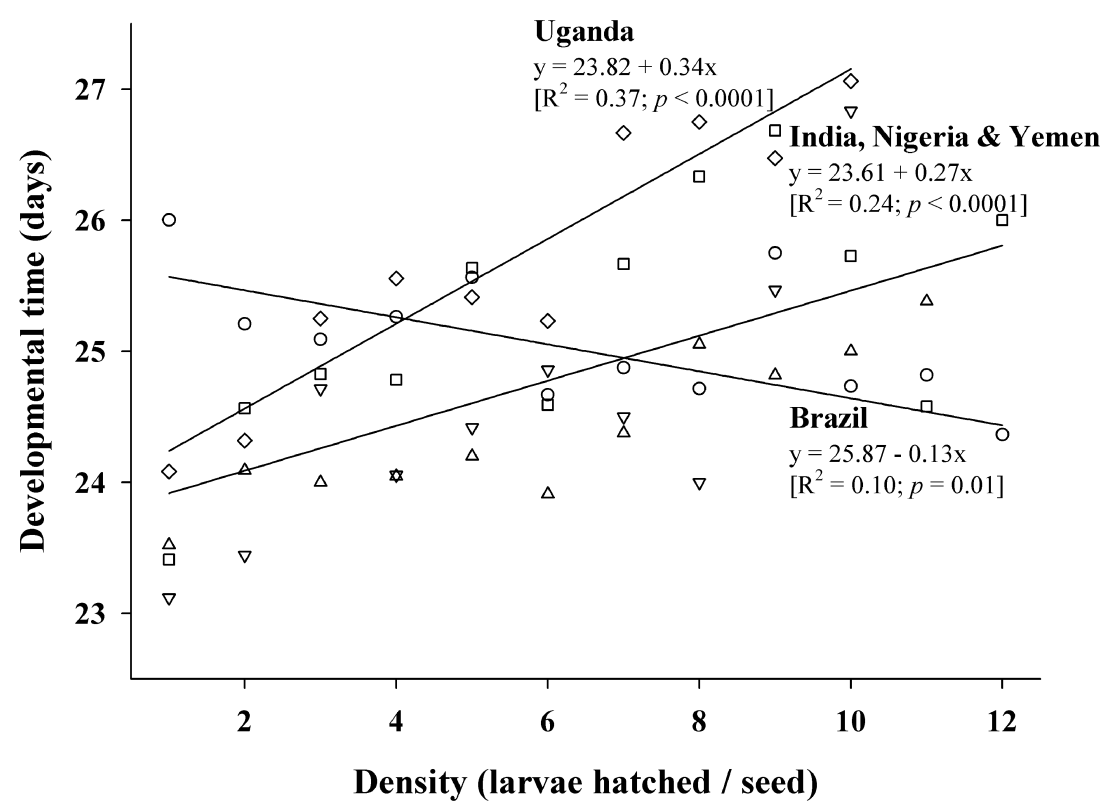

Fig. 4. Developmental time (days) of insects from five strains of Callosobruchus maculatus subjected to increasing levels of larval competition in cowpea seeds. Each symbol represents the mean of the observed results for each strain $[$ Brazil $(O)$, India $(\nabla)$, Nigeria $(\square)$, Uganda $(\diamond)$, Yemen $(\triangle)$ ].

\section{DISCUSSION}

The competition outcome, as currently demonstrated, is a population-level result of larval behaviour (an individual-based process of competition) and resource availability and quality. The competition outcome is therefore dependent of the insect strain, in the case of C. maculatus (Smith \& Lessells 1985; Smith 1990; Horng 1997; Takano et al. 2001), and host seed, particularly its size (Smith 1990; Toquenaga \& Fujii 1991; Toquenaga 1993; Tuda \& Iwasa 1998; Guedes et al. 2003a,b; Messina 2004). Seed size is recognized as a determinant factor in the intensity of larval competition therefore influencing the competition outcome (Smith 1990; Toquenaga 1993; Tuda \& Iwasa 1998; Takano et al. 2001; Messina 2004).

The intensity of competition was determined in our study by the adult emergence curves as a function of density of larvae hatched per seed, but it was not strictly linked to seed size. Higher intensity of competition occurred with the India strain in both seed hosts, and it was even higher in the small seeds of mung bean, as was expected based on the higher respiration rate, seed consumption and weight at the emergence of insects from this strain (Guedes et al. 2003a). In contrast, competition was intense in the Brazil strain without any apparent difference due to host species (or size) and competition was of low intensity for the Yemen strain, also regardless of the host seed. These results were not expected since the Brazil strain is well adapted to larger seeds, which should lead to less intense competition while the Yemen strain, with heavier insects due to their higher respiration rate and seed consumption (Credland \& Dick 1987; Guedes et al. 2003a,b), was expected to exhibit more intense competition, particularly in the smaller seeds of mung bean. The Brazil strain showed intense larval competition on both hosts and the Yemen strain showed poorer performance in mung bean relaxing the competition due to the higher larval mortality in these host seed. The higher intrinsic mortality of Yemen insects in mung bean illustrates the relevance of seed species, rather than merely seed size, for the intensity of competition.

Larval competition was observed in all of the strains of $C$. maculatus and the scramble process was recognized for the four strains either collected or maintained in larger host seeds, as expected. However, the intensity of such competition does not seem to be directly linked to the process of competition, which was evidenced here through the curves of adult weight at emergence as a function of density of larvae hatched per seed. Even under intense competition, as in cowpea seeds infested with larvae from Brazil and India, both processes of competition (i.e. contest and scramble) may take place as observed in these strains. All except the India strain declined in weight at emergence with increased competition, results typical of the scramble process of competition where there is accommodation in resource exploitation with limited resource availability for individual organisms. In contrast, the weight of emerged adults of the India strain 

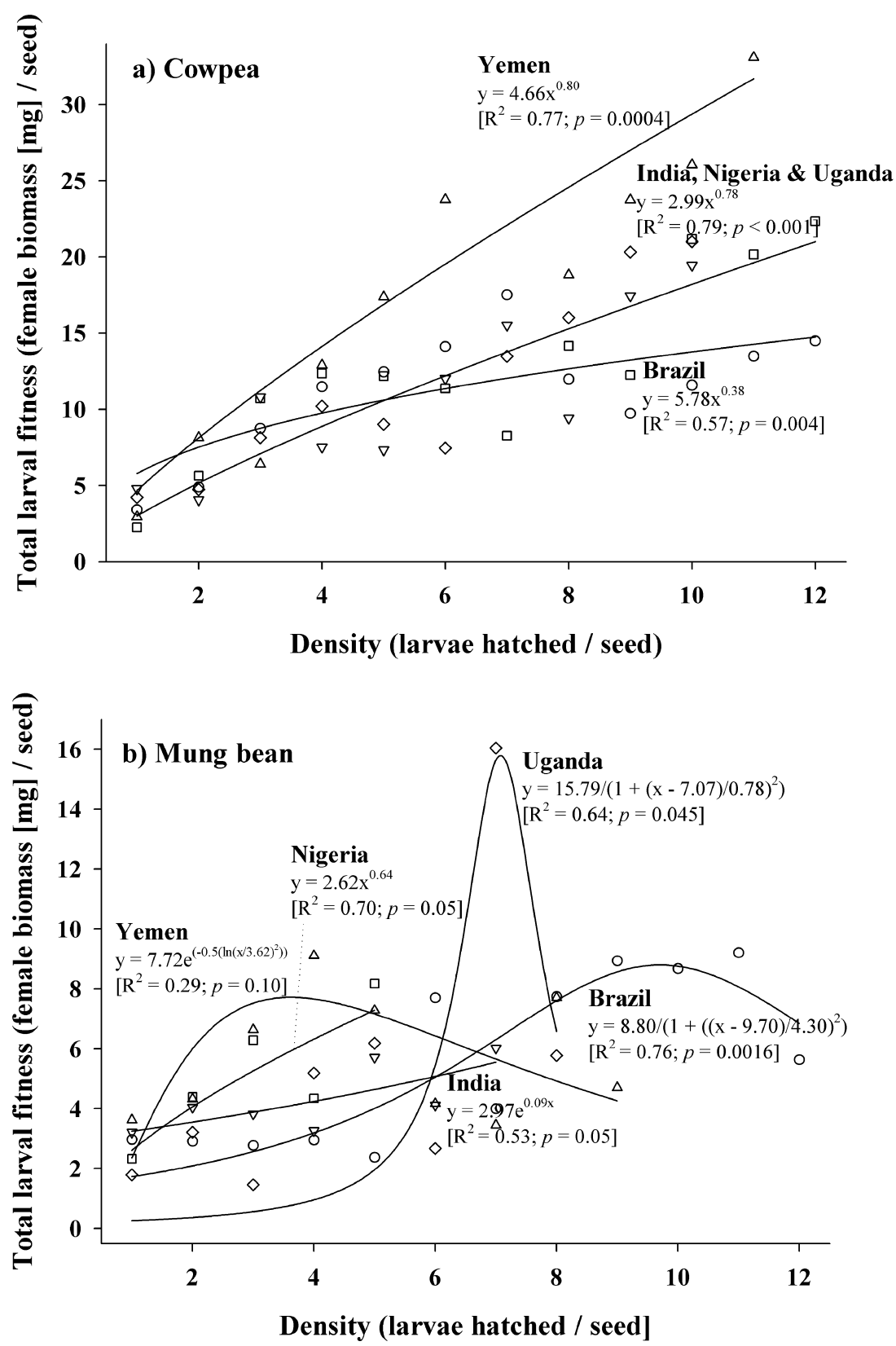

Fig. 5. Larval fitness curves (female body mass/seed) of five strains of Callosobruchus maculatus subjected to increasing levels of larval competition in seeds of two host species, cowpea and mung bean. An exponential model was used to fit the data on cowpea showing a slight bend around the density of six larvae hatched/seed. Each symbol represents the mean of the observed results for each strain $[\operatorname{Brazil}(\bigcirc)$, India $(\nabla)$, Nigeria $(\square)$, Uganda $(\diamond)$, Yemen $(\triangle)$ ].

was not affected by the density of larvae hatched within the seed - a typical result of a contest type of competition process.

The scramble process of competition found in four of the strains studied led to distinct outcomes, as predicted in earlier game theoretical models of larval competition (Smith \& Lessells 1985; Smith 1990; Colegrave 1994, 1995, 1997). Nevertheless, we did not observe the expected prevalence of the scramble outcome in cowpea seeds and of contest outcome in mung bean for strains usually showing the scramble process of competition. Here the competition outcome in cowpea could not be clearly recognized probably due to the limitation imposed by the maximum number of eggs laid per female on each host seed, the same shortcoming observed in mung bean for the Nigeria strain. In contrast, the scramble outcome was observed in the Brazil, Uganda and Yemen strains. The humped curves of larval competition for estimates of total larval fitness obtained for these last three strains 
Table 2. Analysis of covariance of larval fitness (female body mass/seed; log transformed) of five strains of Callosobruchus maculatus subjected to different larval densities in seeds of cowpea

\begin{tabular}{lrrc}
\hline Source of variation & d.f. & $F$ & $P$ \\
\hline Model & 54 & 169.18 & $<0.001^{\star}$ \\
Error & 138 & & \\
Strain (S) & 4 & 89.48 & $<0.001^{\star}$ \\
Larval density (D) & 11 & 707.69 & $<0.001^{\star}$ \\
S $\times$ D & 39 & 30.52 & $<0.001^{\star}$ \\
\hline
\end{tabular}

*Significant at $P<0.05$.

indicate optimal clutch sizes of 10, 7 and 3 larvae per seed in mung bean. Optimal clutch size for the other types of competition investigated here is probably limited by the female egg-laying behaviour. These clutch size differences probably reflect the evolutionary origin of the strains and their subsequent laboratory maintenance, as illustrated by the smaller optimal clutch size of the Yemen strain. This particular strain exhibits high food consumption (Credland \& Dick 1987; Guedes et al. 2003a,b), a likely result of its adaptation to lentils (Credland \& Dick 1987; Smith 1990; Daniel \& Smith 1994), which is coupled with a scramble process and outcome of competition reducing its optimum clutch size.

The larval competition curve expected for a contest type of competition process is a straight line (Smith \& Lessells 1985). This was not observed in the present study. The India strain showed the contest process of competition, but its competition curves were concave with density of larvae hatched showing increased larval fitness with increased larval density up to maximum of 10 and 7 larvae per seed for cowpea and mung bean, respectively. Such maximum clutch size is probably determined by female egg-laying behaviour and the seed host species (including its size) reflecting the amount of suitable food source available for the offspring, which is higher for cowpea than mung bean.

The importance of seed size in the competition outcome of bruchid beetles is widely recognized and reflects the evolutionary trajectories of individual strains (Smith 1990; Toquenaga 1993; Tuda 1998; Tuda \& Iwasa 1998; Takano et al. 2001; Messina 2004), yet it does not fully account for the competition intensity, process and outcome here reported. The legume seed species is often neglected in studies of competition despite earlier warning by Smith (1990). Legume seeds are characterized by a diverse array of mainly nitrogen-based toxins (Bernays \& Chapman 1994; Carlini \& Grossi-de-Sá 2002), and few insects other than bruchids are able to feed on legume seeds. Interstrain differences in respiration rate, developmental rate and body weight have been recently associated with fitness costs of insecticide resistance and their mitigation in grain weevils (Guedes et al. 2006). Such differences exist in the strains of cowpea beetles studied here and are likely to be related to their preferred host species. However, studies of mechanisms and costs of dealing with seed host toxins have yet to be carried out in bruchids. This may have relevant consequences on larval competition and egg-laying behaviour with implications for biotype evolution and host association.

\section{ACKNOWLEDGEMENTS}

We thank the UK Natural Resources Institute, Dr Peter Credland and Dr Frank Messina for providing the original stock strains of $C$. maculatus used in the present study. Financial support was provided by the CAPES Foundation (Brazilian Ministry of Education) and the National Council of Scientific and Technological Development (Brazilian Ministry of Science and Technology). The comments and suggestions provided by the editor, Professor Michael Bull, were greatly appreciated.

\section{REFERENCES}

Alves-Costa C. P. \& Knogge C. (2005) Larval competition in weevils Revena rubiginosa (Coleoptera: Curculionidae) preying on seeds of the palm Syagrus romanzoffiana (Arecaceae). Naturwissenschaften 92, 265-8.

Anderson M. (1978) Natural selection of offspring numbers: some possible intergeneration effects. Am. Nat. 112, 762-6.

Bellows T. S. (1982) Analytical models for laboratory populations of Callosobruchus chinensis and Callosobruchus maculatus (Coleoptera: Bruchidae). F. Anim. Ecol. 51, 263-87.

Bernays E. A. \& Chapman R. H. (1994) Host-Plant Selection by Phytophagous Insects. Chapman \& Hall, New York.

Carlini C. R., Grossi-de-Sá M. F. (2002) Plant toxic proteins with insecticidal properties. A review on their potentialities as biosinsecticides. Toxicon 40, 1515-39.

Colegrave N. (1994) Game theory models of competition in closed systems: asymmetries in fighting and competitive ability. Oikos 71, 499-505.

Colegrave N. (1995) The cost of exploitation competition in Callosobruchus beetles. Funct. Ecol. 9, 191-6.

Colegrave N. (1997) Can a patchy population structure affect the evolution of competition strategies? Evolution 51, 483-92.

Credland P. F. \& Dick K. M. (1987) Food consumption by larvae of three strains of Callosobruchus maculatus (Coleoptera: Bruchidae). F. Stored Prod. Res. 23, 31-40.

Credland P. F., Dick K. M. \& Wright A. W. (1986) Relationships between larval density, adult size and egg production in cowpea seed beetle, Callosobruchus maculatus. Ecol. Entomol. 11, 41-50.

Daniel S. H. \& Smith R. H. (1994) Functional anatomy of the off pore in Callosobruchus maculatus: a trade-off between gasexchange and protective functions? Physiol. Entomol. 19, $30-8$. 
Giga D. P. \& Smith R. H. (1991) Intraspecific competition in the bean weevils Callosobruchus maculatus and Callosobruchus rhodesianus (Coleoptera: Bruchidae). F. Appl. Ecol. 28, 918-29.

Guedes R. N. C., Smith R. H. \& Guedes N. M. P. (2003a) Host suitability, respiration rate and the outcome of larval competition in strains of the cowpea weevil, Callosobruchus maculatus. Physiol. Entomol. 28, 298-305.

Guedes R. N. C., Guedes N. M. P. \& Smith R. H. (2003b) Interstrain variation in larval respiration rate in Callosobruchus maculatus. In: Advances in Stored Product Protection (eds P. F. Credland, D. M. Armitage, C. H. Bell, P. M. Cogan \& E. Highley) pp. 293-6. CAB International, Wallingford.

Guedes R. N. C., Oliveira E. E., Guedes N. M. P., Ribeiro B. \& Serrão J. E. (2006) Cost and mitigation of insecticide resistance in the maize weevil, Sitophilus zeamais. Physiol. Entomol. 31, 30-8.

Horng S.-B. (1997) Larval competition and egg-laying decisions by the bean weevil, Callosobruchus maculatus. An. Behav. 53, $1-12$.

Lale N. E. S. \& Vidal S. (2001) Intraspecific and interspecific competition in Callosobruchus maculatus (F.) and Callosobruchus subinnotatus (Pic) on stored bambara groundnut, Vigna subterranea (L.) Verdcourt. F. Stored Prod. Res. 37, 329-38.

Mano H., Toquenaga Y. \& Fujii K. (2002) Scramble competition in Callosobruchus analis (Coleoptera: Bruchidae). Popul. Ecol. 44, 259-64.

Messina F. J. (1991) Life-history variation in a seed beetle: adult egg-laying vs. larval competitive ability. Oecologia 85, 447-55.

Messina F. J. (2004) Predictable modification of body size and competitive ability following a host shift by a seed beetle. Evolution 58, 2788-97.

Miller R. S. (1967) Pattern and process in competition. Adv. Ecol. Res. 4, 1-74.

Nicholson A. J. (1954) An outline of the dynamics of animal populations. Aust. F. Zool. 2, 9-65.

Nylin S. (2001) Life history perspectives on pest insects: what's the use? Austral Ecol. 26, 507-17.

SAS Institute (1997) SAS/STAT User's Guide, Version 8. SAS Institute, Cary.

Shade R. E., Murdock L. L. \& Kitch L. W. (1999) Interactions between cowpea weevil (Coleoptera: Bruchidae) populations and Vigna (Leguminosae) species. F. Econ. Entomol. 92, $740-5$.

Smith R. H. (1990) Adaptations of Callosobruchus species to competition. In: Bruchids and Legumes: Economics, Ecology and Coevolution (eds K. Fujii, A. M. R. Gatehouse, C. D. Johnson, R. Mitchell \& Y. Yoshida) pp. 351-60. Kluwer, Dordrecht.

Smith R. H. (1991) Genetic and phenotypic aspects of lifehistory evolution in animals. Adv. Ecol. Res. 21, 63-120.

Smith R. H. \& Lessells C. M. (1985) Oviposition, ovivide and larval competition in granivorous insects. In: Behavioural Ecology: Ecological Consequences of Adaptative Behaviour (eds R. M. Sibly \& R. H. Smith) pp. 423-48. Blackwell, London.

Southgate B. J. (1978) The importance of the Bruchidae as pests of grain legumes, their distribution and control. In: Pests of Grain Legumes: Ecology and Control (eds S. R. Singh, H. F. van Emden \& T. A. Taylor) pp. 219-29. Academic, New York.

Southgate B. J., Howe R. W. \& Brett G. A. (1957) The specific status of Callosobruchus maculates (F.) and C. analis (F.). Bull. Entomol. Res. 48, 79-89.

SPSS (2000) Sigmaplot 2000: User's Guide. SPSS, Chicago.

Takano M., Toquenaga Y. \& Fujii K. (2001) Polymorphism of competition type and its genetics in Callosobruchus maculatus (Coleoptera: Bruchidae). Popul. Ecol. 43, 265-73.

Timms R. (1998) Size-independent effects of larval host on adult fitness in Callosobruchus maculatus. Ecol. Entomol. 23, 480-3.

Toquenaga Y. (1993) Contest and scramble competitions in Callosobruchus maculatus (Coleoptera: Bruchidae) II. Larval competition and interference mechanisms. Res. Popul. Ecol. 35, 57-68.

Toquenaga Y. \& Fujii K. (1991) Contest and scramble competitions in Callosobruchus maculatus (Coleoptera: Bruchidae). I. Larval competition curves and resource sharing patterns. Res. Popul. Ecol. 33, 199-212.

Tran B. M. D. \& Credland P. F. (1995) Consequences of inbreeding for the cowpea seed beetle, Callosobruchus maculatus (F.) (Coleoptera: Bruchidae). Biol. F. Linn. Soc. 56, 483-503.

Tuda M. (1998) Evolutionary character changes and population responses in an insect host-parasitoid experimental system. Res. Popul. Ecol. 40, 293-9.

Tuda M. \& Iwasa Y. (1998) Evolution of contest competition and its effect on host-parasitoid dynamics. Evol. Ecol. 12, $855-70$.

Vamosi S. M. (2005) Interactive effects of larval host and competition on adult fitness: an experimental test with seed beetles (Coleoptera: Bruchidae). Funct. Ecol. 19, 859-64.

Varley G. C., Gradwell G. R. \& Hassell M. P. (1973) Insect Population Ecology. Blackwell, Oxford. 